\title{
CS-US interval and suppression of unconditioned vocalization to shock: Associative or non-associative
}

\section{PIETRO BADIA, R. H. DEFRAN, and PAUL LEWIS, Bowling} Green State University, Bowling Green, Ohio 43402

Two experiments are reported in which distress vocalizations to shock (UR) were studied while varying signaled (CS) and unsignaled shock (US), strains, and seven different CS-US intervals (ISI) from $100 \mathrm{msec}$ to $6 \mathrm{sec}$. Measures analyzed were total vocalizations, vocalizations on Trial 1, and distribution of vocalizations over the 2 sec shock. ISIs of 300 msec or less did not suppress vocalizations while ISIs from .5 to $6 \mathrm{sec}$ did $(p<.001)$, but not differentially. CS suppression of the UR occurred on Trial $I(p<.001)$ and continued for all trials. Albinos vocalized more than hoods $(p<.01)$. A nonassociative interpretation was supported.

A finding of significant empirical and theoretical interest is that the number of rat distress vocalizations (UR) elicited by shock (US) is attenuated when shock is preceded by a conditioned stimulus (CS) (Badia, Suter, \& Lewis, 1966). Attenuation of the UR by the CS occurs with either a visual or auditory stimulus and with either a between- or within-Ss experimental design (Badia, Lewis, \& Suter, 1967). Similar CS attenuation of the UR has been found in rats with the GSR (Lykken, 1962) and in humans with the eyeblink response (Kimble \& Ost, 1962) and GSR (Kimmel, 1966).

Different interpretations have been provided regarding UR diminution with both associative and nonassociative factors stressed.

The present study investigated to what extent associative and nonassociative factors are involved in UR diminution by analyzing vocalizations across trials, especially the first trial, over a wide range of CS-US intervals.

\section{METHOD}

\section{Subjects}

Subjects were 56 naive, female hooded and albino rats. The hooded rats $(\mathrm{N}=28)$ were obtained from the colony maintained at Bowling Green State University. The albino rats $(\mathrm{N}=28)$ were obtained from the Holtzman Company, Madison, Wisconsin. All Ss were 80-110 days of age, maintained with a 12-h light-dark cycle in individual cages on ad lib food and water.

Apparatus

The test chamber was a clear Plexiglas compartment $9 \times 6 \times 7 \frac{1}{2}$ in. with a floor of 3/16-in. stainless steel grid bars. A 2-sec scrambled shock of . $28 \mathrm{~mA}$

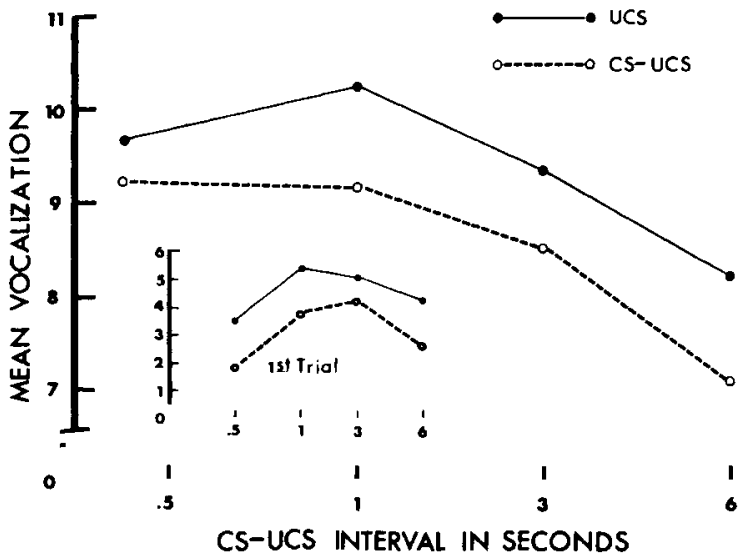

Fig. 1. Mean vocalizations to signaled and unsignaled shock collapsed across strain for each CS-US interval.

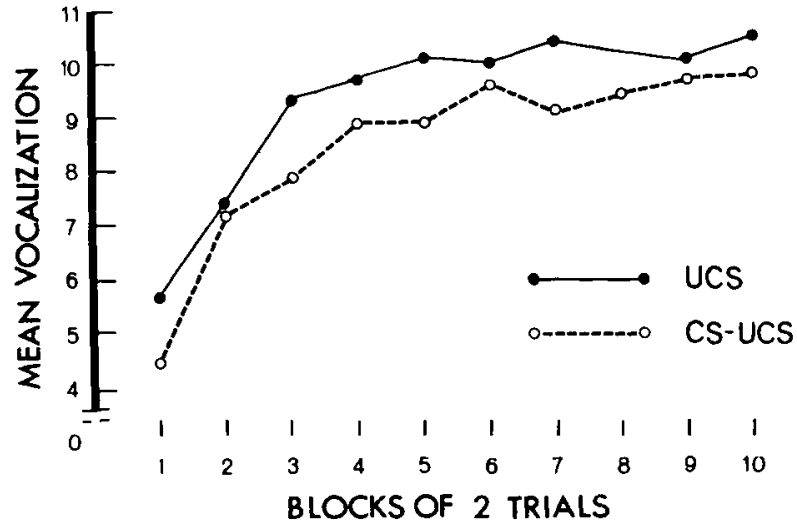

Fig. 2. Mean vocalizations to signaled and unsignaled shock in blocks of four trials collapsed across strain and ISI.

was delivered by a Lehigh Valley constant current source. A Grason-Stadler white noise generator delivered the $80-\mathrm{dB} C S$ to $S$ via a 7 -in. speaker mounted 20 in. from the test chamber. The Plexiglas chamber and speaker were enclosed in a ventilated acoustical chamber with an ambient noise level of $42 \mathrm{~dB}$ as measured on the $\mathrm{C}$ scale of a General Radio sound level meter.

Vocalization Measurement

Vocalization was picked up by an Ampex (Model 2001) microphone placed in the ceiling of the Plexiglas chamber and amplified by an Ampex 1000 tape recorder. To eliminate low frequency noises below $1500 \mathrm{cps}$ caused by S movement, the signal was filtered by an HPM-1500 UTC filter. After being filtered the signal was fed into a Tektronic $2 \mathrm{~A} 60$ vertical amplifier. An external trigger system, activated by shock onset was used to trigger a Tektronic 2B67 time-base unit. Vocalizations were displayed and stored on the screen of a Tektronic 564 storage oscilloscope. The scope was calibrated such that an $80-\mathrm{dB}$ white noise signal within the acoustical chamber yielded $2 \frac{1}{2} \mathrm{~cm}$ on the screen.

Vocalization Criterion

All peaks of $1 \mathrm{~cm}$ above baseline as well as $1-\mathrm{cm}$ changes within peaks were scored as discrete vocalizations. The total number of these discrete vocalizations occurring during the 2 -sec shock was used as the frequency measure of vocalization.

Procedure

An equal number of hooded and albino Ss were randomly assigned to one of four CS-US interval groups $(.5,1,3$, and $6 \mathrm{sec})$. Each $S$ received both CS-US and US-alone trials. Twenty CS-US trials were randomly inserted between 20 US-alone trials with the restriction that neither signal condition could occur more than two times in succession. The sequence of CS.US and US-alone trials was balanced with half the Ss receiving one order and half the reverse. The CS, when present, terminated with US onset and the intertrial in terval(ITI) was $60 \mathrm{sec}$.

\section{RESULTS}

A mixed four-way analysis of variance was computed with CS-US intervals $(.5,1,3$, and $6 \mathrm{sec})$ and strain comparisons (albino vs hoods) as the between-Ss variable. The US condition (presence or absence of CS) and trial blocks (four trials per block) constituted the within-Ss conditions.

Total Vocalizations

Signaled shock consistently and significantly attenuated vocalizations to shock, $\mathrm{F}=27.5, \mathrm{df}=1 / 48, \mathrm{p}<.001$, but the effect of the intervals was not significant, $F<1$, nor was the interaction between US condition and intervals significant (see Fig. 1). This latter finding would seem unlikely if associative processes were soley responsible for CS diminution of the UR. 
Table 1

Mean Number of Vocalizations to Shock for Albino and Hooded Rats in Blocks of 4 Trials

\begin{tabular}{|c|c|c|c|c|c|c|c|c|c|c|}
\hline Trials & l & 2 & 3 & 4 & 5 & 6 & 7 & 8 & 9 & 10 \\
\hline & 7.29 & 8.14 & 10.06 & 10.80 & 11.11 & 11.33 & 11.47 & 11.71 & 11.99 & 12.18 \\
\hline Hooded & 3.03 & 5.60 & 7.91 & 7.91 & 7.92 & 8.39 & 8.14 & 7.99 & 7.91 & 8.22 \\
\hline
\end{tabular}

Further evidence against an associative interpretation is the finding that US conditions and trial blocks did not interact (Fig. 2). Presumably, if associative processes were responsible for reduced vocalizing, the curves would diverge with continued training.

Differences in vocalizations to shock between albino and hooded rats as a function of trials and collapsed across shock conditions (signaled vs unsignaled) and CS-US intervals can be seen in Table 1. Albinos vocalized significantly more frequently to shock than did hoods and this occurred at each CS-US interval, $\mathrm{F}=7.2$, $\mathrm{df}=1 / 48, \mathrm{p}<.01$. The gradually increasing vocalization growth curves to shock is similar to previous findings (Badia et al, 1966, 1967) and is an extremely reliable phenomenon with each S.

First Trial Analysis

An analysis was made contrasting vocalization on the first signaled vs unsignaled shock trial (see Fig. 1). The analysis indicated that the presence of the signal resulted in significantly fewer vocalizations ( $32 \%$ reduction) than the shock-alone condition, $\mathrm{F}=10.9, \mathrm{df}=1 / 48, \mathrm{p}<.001$. It is interesting to note that the $C S$ reduced the number of squeals the first time it was presented in all eight groups ( 2 strains by 4 ISIs). Finding these significant differences at the beginning of training strongly supports a nonassociative interpretation.

Quartile Analysis

It is possible that perhaps a startle response to the CS might be incompatible with vocalizations. That is, a nonassociative startle response to the CS might momentarily inhibit vocalizations on CS-US trials but not on US alone trials. Given this, one would expect the distribution of vocalizations over the 2-sec shock to be different for the two types of trials. Presumably differences should emerge in only the first half-second of shock if startle to the CS is a factor. Fig. 3 shows the quartile distribution of vocalizations over the 2-sec shock period. The distribution shapes are nearly identical for both conditions even though significantly fewer vocalizations

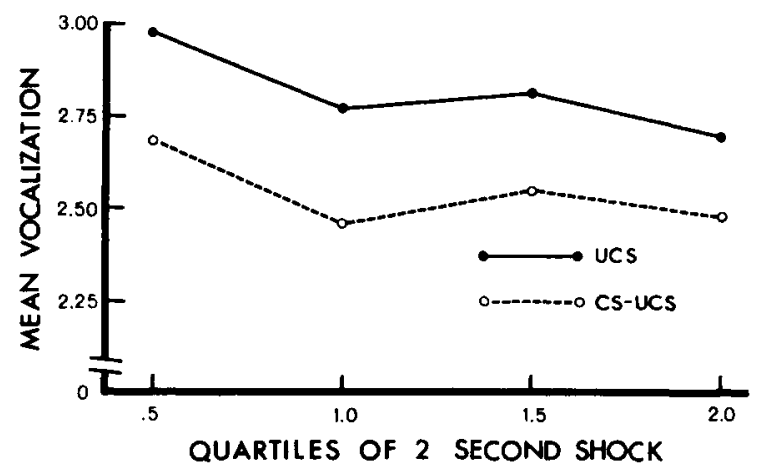

Fig. 3. Quartile distribution of mean vocalizations over the $2 \mathrm{sec}$ shock period. occurred when the CS preceded shock. An interpretation stressing an incompatible startle response to the $C S$ is obviously not supported.

\section{DISCUSSION AND SUMMARY}

Several theoretical notions can be offered in an attempt to explain these data. Assuming that frequency of vocalizing reflects the aversiveness of the US, the finding that Ss emit fewer vocalizations to shock when given a CS appears to support a preparation hypothesis(Perkins, 1955). Thus it might be argued that if preparatory responses (autonomic or skeletal) were made to the CS fewer distress vocalizations to the US would be expected. While this interpretation has some appeal, finding differences on the first trial argues against preparation. This latter finding also argues against a differential arousal interpretation based on the CS clearly defining safe and unsafe periods. A nonassociative interpretation of the data emphasizing incompatible startle responses to the CS also fails to be supported since the vocalization distributions across quartiles were highly similar. Perhaps a "sensory gating notion" similar to that suggested by Melzak \& Wall (1965) is applicable to these data.

\section{EXPERIMENT 2}

Attenuation of vocalizations occurred with CS-US intervals as short as .5 and as long as $6 \mathrm{sec}$ but not differentially. Since intervals shorter than those used in the first experiment have been shown to be effective, the following experiment studied very short ISIs on UR diminution.

\section{METHOD AND RESULTS}

Twenty-four naive, female albino rats between $80-110$ days served as Ss. The apparatus and procedure were identical to that of Experiment 1. An equal number of Ss were randomly assigned to one of three CS-US interval groups (100, 200, 300 $\mathrm{msec}$ ). The results showed that vocalization curves for shock alone and shock preceded by an auditory CS were almost identical. While vocalization to shock preceded by a CS was slightly less in number for all three ISI groups, the differences were not significant, $F=1.45$. Whatever process may be involved in UR diminution, our data suggest the process is not responsive to very short ISIs.

\section{REFERENCES}

BADIA, P., LEWIS, P., \& SUTER, S. Suppression of rat vocalizations to shock by an auditory CS. Psychological Reports, 1967, 20, 1063-1067.

BADIA, P., SUTER, S., \& LEWIS, P. Rat vocalization to shock with and without a CS. Psychonomic Science, 1966, 4, 117-118.

KIMBLE, G., \& OST, J. A conditioned inhibitory process in eyelid conditioning. Journal of Experimental Psychology, 1961, 61, 150-156.

KIMMEL, H. Inhibition of the unconditioned response in classical conditioning. Psychological Review, 1966, 73, 232-240.

LYKKEN, D. T. Preception in the rat: Autonomic response to shock as function of length of warning interval. Science, 1962, 137, 665-666. MELZAK, R., \& WALL, W. D. Pain mechanisms: A new theory. Science, $1965,150,971-979$.

PERKINS, C. C., JR. The stimulus conditions which follow learned responses. Psychological Review, 1955, 62, 341-348.

$$
\text { NOTE }
$$

1. This research was supported in part by USPHS Grant MH 13054-0I to the first author and PHS Fellowship MH 33936-01 from NIMH to the third author. 